\title{
Cardiovascular Reflexes in Workers Exposed to Hand-arm vibration
}

\author{
HANNU VIROKANNAS \\ Oulu Regional Institute of Occupational Health P.O. Box 451, SF-90101 \\ Oulu, Finland
}

Received for publication May 22, 1989

\begin{abstract}
Summary: In the present study autonomic function was observed by measuring cardiovascular reflexes. The quiet breathing test, the deep breathing test and the Valsalva manoeuvre were used. The aim was to study the effects of long-term exposure to hand-arm vibration on the cardiovascular reflexes. The study group included 47 workers (lumberjacks and railroad workers) who were exposed to hand-arm vibration. $36 \%$ of the subjects had vibration induced white finger (VWF). Comparisons were also made with 5 primary Raynaud's cases. The changes of the $R-R$ interval in the quiet and deep breathing tests had a significant negative correlation with the ages of the subjects. In all the results there was no evidence that hand-arm vibration could cause autonomic dysfunction in general, but there were signs that it could reduce the autonomic function among workers who are susceptibility to developing white finger reactions. Also, it is possible that the primary Raynaud's cases had reduced cardiovascular reflex responses.
\end{abstract}

Key words: autonomic dysfunction - cardiovascular reflexes - primary Raynaud's disease - vibration exposure - vibration white finger

\section{Introduction}

It has been suggested in Japan and the USSR that hand-arm vibration can impair the central nervous system, including the higher centers of the autonomic nervous system (Gemne, 1983b; Matoba et al. 1983). Insomnia, vertigo, headaches, depression, fatigue and impotence have been linked with long-term exposure to hand-arm vibration (Matoba et al. 1977; Miyashita et al. 1982). Opposing evidence has also been published. Brammer (1983) did not find a functional dose-response relationship between any neurovegetative symptoms and the operation of vibration tools, when he analysed the data presented earlier. Also Gemne (1983a) concluded that there were no data showing functional anatomical changes in a defined part of the dien- cephalon in vibration exposed workers.

Cardiovascular reflexes have been used to examine the autonomic nervous system in clinical neurology (Bannister et al. 1977; Ewing et al. 1981). Heinonen et al. (1987) have presented a study, where exposure to hand-arm vibration correlated to the decrease of parasympathetic activity during the deep breathing test by forest workers.

The aim of this study was to determine, whether long-term hand-arm vibration has a negative effect on the autonomic nervous system, as measured by cardiovascular reflexes. An additional aim was to study the differences in reactions of the autonomic nervous system between primary Raynaud's patients, patients with vibration induced white finger (VWF) and symptomless vibration exposed workers. 


\section{Materials and Methods}

The study group included 34 railroad workers and 13 lumber jacks, who had been exposed to vibration from chainsaws and track repairing machines. $36 \%$ of the subjects had had white finger symptoms. Exposure to vibration and hand symptoms matched vibration white finger (VWF) in them. Subjects with diabetes and collagenous diseases were excluded by blood sampling, and those with heart diseases and other serious diseases were excluded by clinical examination. Comparisons were also made with 5 primary Raynaud's cases. They had had an attack of white finger before exposure to vibration and the first attack had occurred before they were 25 years old.

Effects of hand-arm vibration were studied in three exposure groups. The subjects in the VIB I group had been exposed to hand-arm vibration for less than $5500 \mathrm{~h}$, in the VIB II group for $5500-10000 \mathrm{~h}$ and in the VIB III group for more than 10000h (Table 1).
The VIB I group was younger than the others (Table 1 ). $54 \%$ of the subjects in the VIB I group, $67 \%$ in the VIB II group and $53 \%$ in the VIB III group were smokers. In total only $9 \%$ of the subjects had never smoked.

Differences in the responses of the autonomic nervous system were clarified for primary Raynaud's cases, VWF cases and symptomless vibration exposed workers (Table 2).

The subjects in the VWF group were older and those in the primary Raynaud's group were younger than the controls. Exposure to vibration had been equal in the VWF cases and the controls (Table 2). $69 \%$ of VWF cases, $40 \%$ of primary Raynaud's cases and $52 \%$ of controls were smokers.

The cardiovascular reflexes were determined from the $\mathrm{R}-\mathrm{R}$ intervals during the quiet breathing test, the deep breathing test and the Valsalva manoeuvre. The measurements were made with a Sport Tester with an accuracy of $\pm 2 \mathrm{~ms}$. The tests were carried out in a supine position

TABLE 1

Age and exposure to hand-arm vibration in the vibration groups

\begin{tabular}{cccc}
\hline Group & N & $\begin{array}{c}\text { Age, yr. } \\
\text { Mean } \pm \text { sd }\end{array}$ & $\begin{array}{c}\text { Exposure to vibration(h) } \\
\text { Mean } \pm \text { sd }\end{array}$ \\
\hline VIB I & 13 & $38.6 \pm 12.0$ & $4000 \pm 1100$ \\
VIB II & 15 & $42.3 \pm 12.3$ & $7400 \pm 1300$ \\
VIB II & 19 & $43.3 \pm 8.5$ & $16300 \pm 8000$ \\
\hline
\end{tabular}

TABLE 2

Age and exposure to hand-arm vibration among VWF, primary Raynaud's and control groups

\begin{tabular}{lrcc}
\hline Group & N & $\begin{array}{c}\text { Age, yr. } \\
\text { Mean } \pm \text { sd }\end{array}$ & $\begin{array}{c}\text { Exposure to vibration(h) } \\
\text { Mean } \pm \text { sd }\end{array}$ \\
\hline VWF & 16 & $45.3 \pm 8.2$ & $10000 \pm 3400$ \\
Primary Raynaud & 5 & $29.6 \pm 7.2$ & $2700 \pm 1800$ \\
Control & 31 & $39.7 \pm 11.5$ & $10100 \pm 8800$ \\
\hline
\end{tabular}


after 10 minutes rest. First, the $R-R$ intervals were measured in the quiet breathing state for 2 minutes. Heart rate variation was calculated from 60 successive $\mathrm{R}-\mathrm{R}$ intervals. The mean square root of the differences of the $\mathrm{R}-\mathrm{R}$ intervals (RMSSD) was used as an index of beat to beat variation (Heinonen et al. 1987) and the standard deviation (SD) was used as an index of overall variation (Ewing et al. 1981).

The deep breathing test (6 breaths/ min) for 1 minute was performed twice and the highest indexes of heart rate variation were used. The deep breathing difference (DBD) (Ewing et al. 1981) was calculated as a mean value of the differences between the 5-6 highest (in inspirium) and lowest (in expirium) pulse rates during the test. Also the mean value of the ratio between the 5-6 longest (in expirium) and shortest (in inspirium) $\mathrm{R}-\mathrm{R}$ intervals (E/I) (Sundkvist et al. 1979) was used.

During the Valsalva manoeuvre R-R intervals were measured for 1 minute: for 15 seconds while blowing against a 40 $\mathrm{mmHg}$ pressure and for 45 seconds after that. The Valsalva ratio (VR) (Levin, 1966) was the ratio between the longest $\mathrm{R}-\mathrm{R}$ interval after blowing and the shortest during blowing. The highest ratio from two measurements was used.

\section{Results}

The effect of long-term exposure to handarm vibration

The variations of the $R-R$ intervals during the quiet and deep breathing tests were smallest in the groups that used vibration tools the most. However, the differences were not statistically significant (Table 3 and 4). The Valsalva ratio was the smallest in the VIB II group (Table 4).

TABLE 3

Heart rate variation during a quiet breathing test among workers exposured to hand-arm vibration

\begin{tabular}{ccccc}
\hline Group & N & $\begin{array}{c}\text { RMSSD, ms } \\
\text { Mean } \pm \text { sd }\end{array}$ & $\begin{array}{c}\text { MEAN, ms } \\
\text { Mean } \pm \text { sd }\end{array}$ & $\begin{array}{c}\text { SD } \\
\text { Mean } \pm \text { sd }\end{array}$ \\
\hline VIB I & 13 & $21.8 \pm 10.4$ & $1019 \pm 195$ & $38.8 \pm 16.3$ \\
VIB II & 15 & $20.8 \pm 13.4$ & $1000 \pm 244$ & $34.4 \pm 18.9$ \\
VIB III & 19 & $18.3 \pm 11.4$ & $962 \pm 116$ & $34.1 \pm 13.6$ \\
\hline
\end{tabular}

RMSSD $=$ root mean square successive difference, $M E A N=$ mean of $R \cdot R$ intervals and $S D=$ standard deviation of $R \cdot R$ intervals

TABLE 4

Heart rate variation during a deep breathing test and a Valsalva maneouver among workers exposured to hand-arm vibration

\begin{tabular}{ccccc}
\hline Group & N & $\begin{array}{c}\text { DBD } \\
\text { Mean } \pm \text { sd }\end{array}$ & $\begin{array}{c}\text { E/I } \\
\text { Mean } \pm \text { sd }\end{array}$ & $\begin{array}{c}\text { VR } \\
\text { Mean } \pm \text { sd }\end{array}$ \\
\hline VIB I & 13 & $15.9 \pm 6.5$ & $1.28 \pm 0.12$ & $1.55 \pm 0.28$ \\
VIB II & 15 & $15.4 \pm 7.0$ & $1.27 \pm 0.14$ & $1.44 \pm 0.24$ \\
VIB III & 19 & $14.5 \pm 6.0$ & $1.25 \pm 0.11$ & $1.48 \pm 0.19$ \\
\hline
\end{tabular}

$\mathrm{DBD}=$ deep breathing difference, $\mathrm{E} / \mathrm{I}=$ ratio of $\mathrm{R}-\mathrm{R}$ intervals in expirium and inspirium and $\mathrm{VR}=$ Valsalva ratio 
For the quiet breathing test the age of the subjects had a significant correlation to the standard deviation of the $\mathrm{R}-\mathrm{R}$ intervals $(\mathrm{r}=-0.41, \mathrm{p}<0.0024)$ and to the RMSSD ( $r=-0.65, p<0.0001)$. Also in the deep breathing test, the age and the indexes correlated significantly (DBD:r $=$ $-0.53, \quad \mathrm{p}<0.0001$ and $\mathrm{E} / \mathrm{I}: \mathrm{r}=-0.54, \mathrm{p}<$ $0.0001)$. The Valsalva ratio had no relationship to age. The exposure to vibration had no significant linear correlation to the indexes of the heart rate variation in any tests.

Since age had an effect on the test results, a comparison was also made of the groups under and over 45 years of age (Fig. 1). There were no statistically significant differences between the vibration exposure groups.

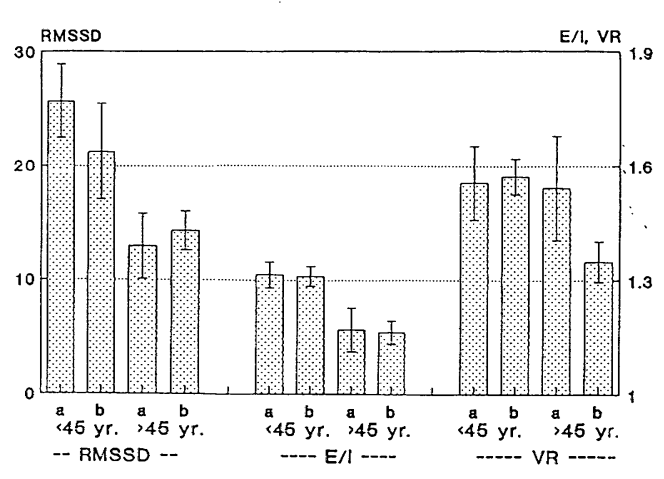

Fig. 1. Heart rate variation in mild $(\mathrm{a}=$ VIB I) and heavy ( $b=$ VIB III) exposure groups to hand-arm vibration according to age. Means and standard errors have been drawn in the figure.

$\mathrm{RMSSD}=$ root mean square successive difference, $E / I=$ ratio of $R-R$ intervals in expirium and inspirium and $\mathrm{VR}=$ Valsalva ratio.

TABLE 5

Heart rate variations during the quiet breathing test among VWF, primary Raynaud's and control groups

\begin{tabular}{lrrrr}
\hline \multicolumn{1}{c}{ Group } & N & $\begin{array}{c}\text { RMSSD ms, } \\
\text { Mean } \pm \text { sd }\end{array}$ & $\begin{array}{c}\text { MEAN, ms } \\
\text { Mean } \pm \text { sd }\end{array}$ & $\begin{array}{c}\text { SD } \\
\text { Mean } \pm \text { sd }\end{array}$ \\
\hline VWF & 16 & $15.8 \pm 5.3^{*}$ & $940 \pm 114$ & $32.7 \pm 9.5$ \\
Primary Raynaud & 5 & $17.3 \pm 5.7$ & $1060 \pm 181$ & $28.1 \pm 8.3$ \\
Control & 31 & $22.3 \pm 13.4$ & $1015 \pm 209$ & $37.0 \pm 18.4$ \\
\hline
\end{tabular}

RMSSD $=$ root mean square successive difference, $M E A N=$ mean of $\mathrm{R}-\mathrm{R}$ intervals and $\mathrm{SD}=$ standard deviation of $\mathrm{R}-\mathrm{R}$ intervals T-test: ${ }^{*} \mathrm{p}<0.023$

TABLE 6

Heart rate variations during the deep breathing test and Valsalva maneouver among VWF, primary Raynaud's and control groups

\begin{tabular}{lrccc}
\hline \multicolumn{1}{c}{ Group } & N & $\begin{array}{c}\text { DBD } \\
\text { Mean } \pm \text { sd }\end{array}$ & $\begin{array}{c}\text { E/I } \\
\text { Mean } \pm \text { sd }\end{array}$ & $\begin{array}{c}\text { VR } \\
\text { Mean } \pm \text { sd }\end{array}$ \\
\hline VWF & 16 & $13.8 \pm 6.9$ & $1.23 \pm 0.12$ & $1.48 \pm 0.18$ \\
Primary Raynaud & 5 & $16.3 \pm 5.8$ & $1.27 \pm 0.09$ & $1.63 \pm 0.26$ \\
Control & 31 & $15.9 \pm 6.0$ & $1.28 \pm 0.12$ & $1.49 \pm 0.25$ \\
\hline
\end{tabular}

$\mathrm{DBD}=$ deep breathing differences, $\mathrm{E} / \mathrm{I}=$ ratio of $\mathrm{R}-\mathrm{R}$ intervals in expirium and inspirium and $\mathrm{VR}=$ Valsalva ratio 


\section{Autonomic function tests in patients with white finger}

The responses in the VWF group during the quiet and deep breathing tests were smaller than for the control group. However, the Valsalva ratio was nearly the same (Table 5 and 6). Also in the primary Raynaud's group, the heart rate variation during the quiet breathing test was smaller than in the control group, but the differences were not significant. The DBD and the Valsalva ratio were greatest in the primary Raynaud's group (Table 6).

A comparison was also made of the groups under and over 45 years of age (Fig. 2). The biggest difference between the VWF cases and the controls was in the RMSSD of the young subjects and in the E/I and VR of the older subjects. The differences were not statistically significant (Fig. 2).

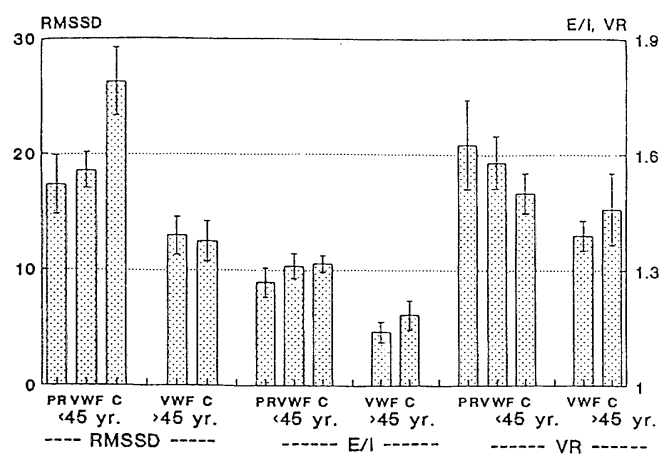

Fig. 2. The heart rate variation in the VWF, primary Raynaud's (PR) and control (C) groups in two age ranges. Means and standard errors have been drawn in the figure.

RMSSD $=$ root mean square successive difference, $E / I=$ ratio of $R-R$ intervals in expirium and inspirium and $V R=$ Valsalva ratio.

\section{Discussion}

Many diseases can reduce the function of the autonomic nervous system (Bannister et al. 1977; Turkka, 1986; Havanka-Kanniainen, 1986). Autonomic neuropathy has often been studied by observing the cardiovascular reflexes in diabetics (Ewing et al. 1981; Mackay et al. 1980). Reduced autonomic responses have also been reported in alcoholics (Matikainen et al. 1986) and after longterm exposure to organic solvents (Matikainen and Juntunen, 1985). Piha (1988) has reported that smoking has a negative effect on the Valsalva ratio and $\mathrm{DBD}$. The heart rate variation is known to decrease with age (Wieling et al. 1982; Piha, 1988). The change with age has been smaller for the Valsalva manoeuvre than for the quiet and deep breathing tests (Levin, 1966; Piha, 1988).

In the present study the subjects were selected by clinical examination and blood sampling. Also the workers on medications were excluded. The group included 47 vibration exposed workers and 5 primary Raynaud's cases. The effect of smoking was not taken into account, because only $9 \%$ of the subjects had never smoked. There was a significant connection between the age of the subjects and the indexes for the quiet and deep breathing tests.

There are indications that hand-arm vibration can cause a dysfunction of the autonomic nervous system, and in Japan and the USSR the vibration syndrome is considered to be a systemic disease (Gemne, 1983b; Matoba et al. 1983). Neurovegetative symptoms have been reported in cross-sectional studies among vibration exposed workers (Matoba et al. 1977; Miyashita et al. 1982). According to the analysis of earlier published data Brammer (1983), however, concluded that factors other than exposure to vibration could cause the development of the neurovege- 
tative symptoms. In a study by Heinonen et al. (1987) the heart rate variation was reduced in forestry workers during the quiet breathing test.

In the present study the responses of the heart rate variation were a little smaller in the group which had more frequently used vibration tools. When the age of the subjects was taken into account, there were no differences in the results of the deep breathing tests. The slight difference in the results of the quiet breathing test was opposite to what would be expected for the older group, as compared to the younger group. In the older group the Valsalva ratio was smaller in the heavily exposed workers; but this difference was not significant, either. These results do not provide evidence that hand-arm vibration can cause autonomic dysfunction, in general.

It has been reported that patients who have peripheral somato-sensory neuropathy, often also have an autonomic dysfunction (Matikainen and Juntunen, 1985). For the vibration syndrome it is not clear that this kind of connection occurs.

In some studies a reduced function of the autonomic nervous system has been linked to vibration induced white finger. Matoba et al. (1975) have reported that the VWF patients had delayed recoveries in tests that mesured the responses to auditory stimuli with digital plethysmography. Also the workers with VWF had more hearing damage caused by noise than other workers (Iki et al. 1986; Pyykkö et al. 1987). The function of the autonomic nervous system has been suggested to be a possible explanation (Pyykkö, 1983). In a study of reindeer herders, snowmobile users that had suffered white finger attacks, also had more heart and respiratory symptoms caused by cold (Virokannas et al. 1988). In addition, Futatsuka and Ueda (1982) reported that cold tolerance was decreased in many VWF patients. These findings are probably related to the function of the autonomic nervous system. The cardiovascular reflexes of patients with VWF and controls were not significantly different in a study of forest workers (Heinonen et al. 1987), but only $7 \%$ of the subjects had active white finger.

In the present study the VWF patients had smaller responses at young ages during the quiet breathing test and at older ages during the deep breathing test and Valsalva manoeuvre. The number of the subjects was small and only one difference was statistically significant, however the trend is worth further study. All primary Raynaud's patients were in the young age group, and they had the weakest responses on the quiet and deep breathing tests.

According to these results, exposure to vibration could cause autonomic dysfunction in the workers who have a susceptibility to develop white finger reactions. The primary Raynaud's cases should be studied more in this respect. It is possible that they could have reduced cardiovascular reflex responses.

\section{References}

Bannister, R., Sever, P. and Gross, M. (1977). Cardiovascular reflexes and biochemical responses in progressive autonomic failure. Brain 100, 327-344.

Brammer, A.J. (1983). Dose-response relationships for the hand-arm vibration syndrome, with reference to neurovegetative symptoms. J. Low Freqency Noise Vibr. 1 (special issue), 151-162.

Ewing, D. J., Borsey, D.Q., Bellavere, F. and Clarke, B.F. (1981). Cardiac autonomic neuropathy in diabetes: Comparison of measures of $\mathrm{R}-\mathrm{R}$ interval variation. Diabetologia 21, 18-24.

Futatsuka, M. and Ueda, T. (1982). Quantitative observation on thermal and metabolic responses to cold of workers using vibration tools. Int. Arch. Occup. Environ. Health 49, 213-221.

Gemne, G. (1983a). Autonomic integration of 
external and internal stimuli, and the Soviet concept of "diencephalic syndrome". J. Low Frequency Noise Vibr. 1 (special issue), 6368.

Gemne, G. (1983b). "Vibration disease" as a central nervous system disorder. - Development, symptomatology, and patho-physiology of Soviet and Japanese classifications. J. Low Frequency Noise Vibr. 1 (special issue), 19-35.

Havanka-Kanniainen, H. (1986). Autonomic dysfunction in Migraine. Acta Universitas Ouluensis, series D, medica $n$ :o 143. Academic dissertation. Oulu, Finland: University of Oulu.

Heinonen, E., Färkkilä, M., Forsström, J., Antil , K., Jalonen, J., Korhonen, O. and Pyykкö, I. (1987). Autonomic neuropathy and vibration exposure in forestry workers. Br. J. Ind. Med. 44, 412-416.

Iki, M., Kurumatani, N., Hirata, K., Moriyama, T., Satoh, M. and Arai, T. (1986). Association between vibration-induced white finger and hearing loss in forestry workers. Scand. J. Work Environ. Health 12, 365-370.

Levin, A.B. (1966). A simple test of cardiac function based upon the heart rate changes induced by the Valsalva maneuver. Am. J. Cardiol. 18, 90-99.

Mackay, J.D., Page, M. McB., Cambridge, J. and Watkins, P. J. (1980). Diabetic autonomic neuropathy. The diagnostic value of heart rate monitoring. Diabetologia 18, 471-478.

Matikainen, E. and Juntunen, J. (1985). Autonomic nervous system dysfunction in workers exposed to organic solvents. J. Neurol. Neurosurg. Psych. 48, 1021-1024.

Matikainen, E., Juntunen, J. and Salmi, T. (1986). Autonomic dysfunction in long-standing alcoholism. Alcohol and Alcoholism 21, 69-73.

Matoba, T., Chiba, M. and Inutsuka, S. (1983). Autonomic nervous system disorders in subjects exposed to hand-arm vibration. A review of clinical investigations in Japan. J. Low Frequency Noise Vibr. 1 (special issue), 74-83.

Matoba, T., Kusumoto, H., Mizuki, Y., Kuwahara, H., Inanaga, K. and Takamatsu, M. (1977). Clinical features and laboratory findings of vibration disease: a review of 300 cases. Tohoku J. Exp. Med. 123, 57-65.

Matoba, T., Kusumoto, H., Omura, H., Kotori, T., Kuwahara, H. and Takamatsu, M. (1975). Digital plethysmographic responses to auditory stimuli in patients with vibration disease. Tohoku J. Exp. Med. 115, 385-392.

Miyashita, K., Shiomi, S., Itoh, N., Kasamatsu, T. and Iwata, H. (1982). Development of the vibration syndrome among chain sawyers in relation to their total operating time. In Vibration Effects on the Hand and Arm in Industry. eds. Brammer, A. J. and Taylor, W. pp. 269-276. New York: John Wiley and Sons.

PiHA, J. (1988). Cardiovascular autonomic function tests. Responses in healthy subjects and determination of agerelated reference values. Turku, Finland: Publications of the Social Insurance Institution, $\mathrm{ML}: 85$.

Ручккӧ, I. (1983). Sensory integration of vibratory stimuli. Hand-arm vibration and the central autonomic nervous system. J. Low Frequency Noise Vibr. 1 (special issue), 6973.

Pyykkö, I., Pekkarinen, J. and Starck, J. (1987). Sensory-neural hearing loss during combined noise and vibration exposure. An analysis of risk factors. Int. Arch. Occup. Environ. Health. 59, 439-454.

Sundkvist, G., Almer, L-O. and Lilja, B. (1979). Respiratory influence on heart rate in $\mathrm{di}$ abetes mellitus. Bri. Med. J. 1, 924-925.

TurkKA, J. (1986). Autonomic dysfunction in Parkinson's disease. Acta Universitas Ouluensis, series $\mathrm{D}$, medica $\mathrm{n}: \mathrm{o}$ 142. Academic dissertation. Oulu, Finland: University of Oulu.

Virokannas, H., Anttonen, H. and Niskanen, J. (1988). Effects of multiexposures on the hands in snowmobile driving. In: Manninen, $\mathrm{O}$. (ed.) Recent advances in researches on the combined effects of environmental factors. pp 591-604. Tampere: PK-Paino oy.

Wieling, W., Van Brederode, J.F., Rijk, L. G., Borst, C. and Dunning, A. J. (1982). Reflex control of heart rate in normal subjects in relation to age: A data base for cardiac vagal neuropathy. Diabetologia 22, 163-166. 